\title{
Requirement of Akt to Mediate Long-Term Synaptic Depression in Drosophila
}

\author{
Hui-Fu Guo ${ }^{1,2}$ and Yi Zhong ${ }^{1}$ \\ ${ }^{1}$ Cold Spring Harbor Laboratory, Cold Spring Harbor, New York 11724, and ${ }^{2}$ Blanchette Rockefeller Neurosciences Institute, Rockville, Maryland 20850
}

\begin{abstract}
Drosophila larval neuromuscular junction (NMJ) is a well established preparation enabling quantitative analyses of synaptic physiology at identifiable synapses. Here, we report the first characterization of synaptic long-term depression (LTD) at the Drosophila NMJ. LTD can be reliably induced by specific patterns of tetanic stimulation, and the level of LTD depends on both stimulus frequency and $\mathrm{Ca}^{2+}$ concentration. We provide evidence that LTD is likely a result of presynaptic changes. Through screening of targeted mutants with defects in memory or signal transduction pathways, we found that LTD is strongly reduced in the akt mutants. This defect can be rescued by acutely induced expression of the normal akt transgene, suggesting that altered LTD is not attributable to developmental abnormalities and that Akt is critical for the induction of LTD. Our study also indicates that the molecular mechanisms of LTD are distinct from that of short-term synaptic plasticity, because akt mutants showed normal short-term facilitation and posttetanic potentiation, whereas LTD was unaffected in mutants that exhibit defective short-term synaptic plasticity, such as dunce and rutabaga. The characterization of LTD allows genetic analysis of the molecular mechanisms of long-term synaptic plasticity in Drosophila and provides an additional assay for studying functions of genes pertaining to synaptic and behavioral plasticity.
\end{abstract}

Key words: long-term depression; neuromuscular junction; synaptic plasticity; Drosophila; Akt; short-term plasticity

\section{Introduction}

The larval neuromuscular junction (NMJ) is the only preparation in Drosophila suitable for quantitative analysis of synaptic transmission at identifiable synapses. It has been used extensively to study the molecular basis of synapse development, synaptic plasticity (for review, see Keshishian et al., 1996; Packard et al., 2003), synaptic vesicle release (for review, see Schwarz, 1994; Wu and Bellen, 1997), and functions of genes involved in learning and memory (Zhong and Wu, 1991; Broadie et al., 1997; Guo et al., 1997, 2000; Rohrbough et al., 1999, 2000; DeZazzo et al., 2000). Various forms of short-term synaptic plasticity at the NMJ have been demonstrated, including facilitation, augmentation, posttetanic potentiation, and depression (Jan and Jan, 1978; Zhong and Wu, 1991; Broadie et al., 1997; Delgado et al., 2000; Wu et al., 2005), with durations ranging from seconds to several minutes. These forms of plasticity are disrupted in a number of mutants with defective intracellular signal transduction pathways and impaired learning and memory (Zhong and Wu, 1991; Rohrbough et al., 1999, 2000), such as dunce and rutabaga that express mutated forms of cAMP-specific phosphodiesterase and adenylyl cyclase, respectively (Chen et al., 1986; Levin et al., 1992). However, neither long-term potentiation nor long-term depression

Received March 17, 2004; revised Feb. 8, 2006; accepted Feb. 9, 2006

This work was supported by National Institutes of Health Grant 5R01-NS34779-08 (Y.Z.) and United States Army Grant DAMD17-99-1-9500 (Y.Z.). We thank Dr. Woodgett for kindly providing the dAkt antibody and Drs. Javier Verdu, Morris J. Birnbaum, Armen S. Manoukian, and Ernst Hafen for the akt mutant and transgenic flies. We are grateful to Dr. M. Catherine Bennett for constructive editorial assistance with this manuscript.

Correspondence should be addressed to Yi Zhong, Cold Spring Harbor Laboratory, P.0. Box 100, Cold Spring Harbor, NY 11724. E-mail: zhongyi@cshl.edu.

D01:10.1523/JNEUROSCI.3616-05.2006

Copyright $\odot 2006$ Society for Neuroscience $\quad$ 0270-6474/06/264004-11\$15.00/0
(LTD) has been demonstrated at the glutamatergic synapses of the NMJ. If one of these forms of long-lasting plasticity could be demonstrated at these synapses, it would be possible to use Drosophila genetic tools to analyze the molecular mechanisms of long-term synaptic plasticity.

Accumulating data suggest that the molecular mechanisms for long-term synaptic plasticity exist also at the Drosophila NMJ. Genetic manipulations of these molecules were shown to produce long-term modifications of synaptic strength. For example, synaptic transmission at the NMJ was persistently enhanced in mutants of dunce as a result of elevated levels of cAMP (Zhong and $\mathrm{Wu}, 1991$; Renger et al., 2000) and was reversed by inhibiting the activity of the transcription factor cAMP response elementbinding protein (CREB) (Davis et al., 1998). Genetic manipulations of local protein synthesis, glutamate receptors expression (Sigrist et al., 2000, 2002, 2003), and the activator protein-1 transcription factors (Sanyal et al., 2002) were also shown to modify the synaptic strength at these synapses. Thus, various signaling systems underlying long-term plasticity in vertebrates have also been observed in the synapses of Drosophila NMJ.

Long-term plasticity has been reported at the NMJ of both vertebrates and other invertebrates (Lnenicka and Atwood, 1985; Lo et al., 1994; Cash et al., 1996; Malenka and Nicoll, 1999; Wan and Poo, 1999; Etherington and Everett, 2004). We therefore attempted to induce similar long-term plasticity at the Drosophila larval NMJ. Here we show that LTD can be reliably induced after the delivery of a specific pattern of electrical stimulation to the motor axons. In the present study, we characterized the properties of this newly identified LTD and examined LTD in selected mutant flies. 


\section{Materials and Methods}

Fly care and heat shock treatment. All flies were raised at room temperature (RT) in regular cornmeal food (unless otherwise indicated). To induce the expression of $h s p 70$-akt (normal akt transgene driven by the promoter of heat shock protein 70) in the hsp70-akt;akt ${ }^{1}$ flies, heat shock (HS) treatment $\left(30 \mathrm{~min}\right.$ at $37^{\circ} \mathrm{C}$ water bath) was delivered once a day starting from the embryonic stage (developmental daily HS treatment). This HS treatment to hsp70-akt; $a k t^{l}$ was sufficient to overcome the lethality of the homozygous $a k t^{1}$ mutant allele and provided viable third-instar larvae for electrophysiological analysis. Specifically, flies were allowed to lay eggs for $1 \mathrm{~d}$ in the bottle and then were removed from the bottle. HS treatment began after removing the flies. After the last daily heat shock exposure, the hsp70-akt;akt ${ }^{1}$ larvae were placed at $18^{\circ} \mathrm{C}$ for $24-48 \mathrm{~h}$ to reduce the leaky expression of the hsp70-akt transgene. Some of these larvae were brought to RT for 3-6 h and were then subjected to HS treatment $\left(37^{\circ} \mathrm{C}\right.$, two exposures of $15 \mathrm{~min}, 2 \mathrm{~h}$ interval) (see Fig. $7 \mathrm{~A}, 18^{\circ} \mathrm{C} \rightarrow \mathrm{HS}$ ). Dissection of larvae and recordings for the $18^{\circ} \mathrm{C} \rightarrow \mathrm{HS}$ group was performed at $0.5-2 \mathrm{~h}$ after the second 15 min HS exposure. For control, some larvae were brought to RT from $18^{\circ} \mathrm{C}$ and directly dissected for electrophysiological recordings at RT (see Fig. $7 \mathrm{~A}, 18^{\circ} \mathrm{C}$ ). Some larvae were not placed at $18^{\circ} \mathrm{C}$ but were subjected to dissection and recordings at $24 \mathrm{~h}$ after the last daily HS treatment (see Fig. 7C, RT group) or were treated by the same HS paradigm as for $18^{\circ} \mathrm{C} \rightarrow \mathrm{HS}$ at $24 \mathrm{~h}$ after the daily HS treatment and then subjected to electrophysiological analysis.

Immunohistochemistry and measurement of fluorescence intensity. Immunostaining of Drosophila Akt (dAkt) (1:200) on the larval NMJ was performed according to the method described previously (Rohrbough et al., 2000) using a polyclonal Akt antibody. The secondary antibody was FITC conjugated (1:1000). Fluorescence color images were taken by confocal laser scanning microscopy. For measurement of the staining intensity and for clearer presentation of the staining effect, the fluorescence images were inverted using Scion NIH Image (Scion, Frederick, MD) (see Fig. 9).

Electrophysiology. Electrophysiological recordings of two-electrode voltage clamp were performed as described previously (Stewart et al., 1994; Zhong and Pena, 1995). For optimal long-term recording, wallclimbing third-instar larvae from large fresh bottles (without adult flies in the bottle) were chosen for dissection. Dissections of third-instar larvae were made at RT and in $\mathrm{Ca}^{2+}$-free hemolymph-like (HL-3) solution (Stewart et al., 1994; modified by Feng et al., 2004) containing the following (in mM): $70 \mathrm{NaCl}, 5 \mathrm{KCl}, 4 \mathrm{MgCl}_{2}, 10 \mathrm{NaHCO}_{3}, 5$ trehalose, 5 HEPES, and 115 sucrose. For recordings, HL-3 solution was supplemented with $\mathrm{CaCl}_{2}$ (concentrations are indicated in the text and the figure legends). All recordings were made at the longitudinal muscles of segments A3-A5. To elicit evoked junctional currents (EJCs), the segmental nerve was stimulated at 1.5 times the stimulus voltage required for a threshold response, unless otherwise indicated. For recordings of LTD and controls, continuous recordings were made while the nerve was stimulated at baseline frequency of $0.05 \mathrm{~Hz}$. For induction of LTD, tetanus of defined frequency and duration (see figure legends) was delivered after $\sim 5$ min of baseline stimulation. Methods for induction of short$0.35-0.4 \mathrm{~mm} \mathrm{Ca}^{2+}$.
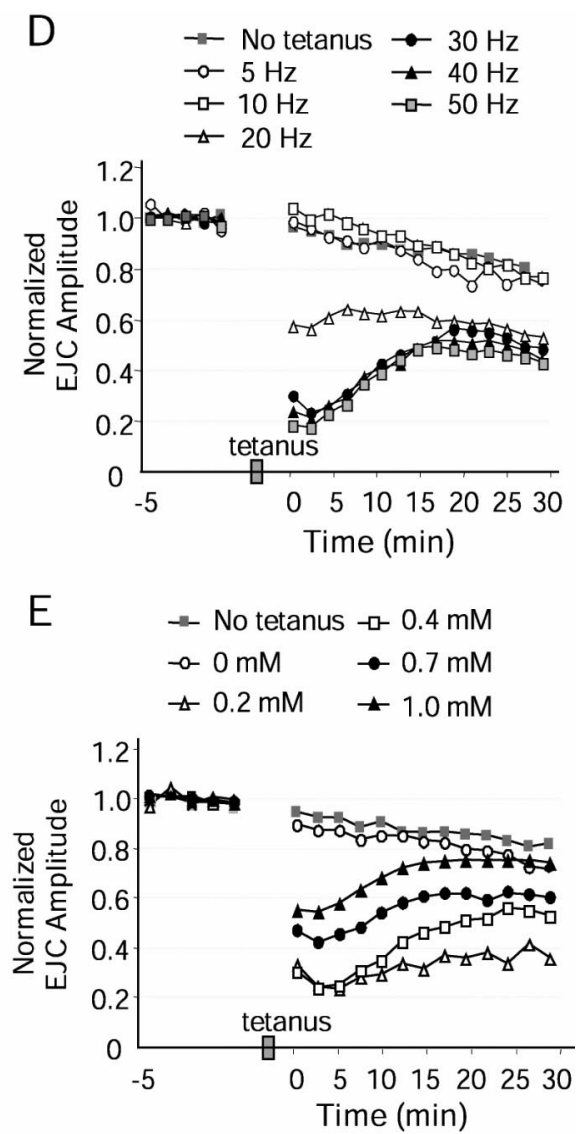

$0 \quad 51015202530$

Time (min)

Figure 1. LTD at the Drosophila NMJ. $\boldsymbol{A}$, Representative recordings of control and LTD induction. EJCs were recorded at the NM 列 induction of LTD, tetanus of $30 \mathrm{~Hz}(20 \mathrm{~s})$ was delivered at $\sim 5$ min after continuous recording. Calibration: $20 \mathrm{nA}, 2 \mathrm{~min} . \boldsymbol{B}$ ummary of normalized EJC amplitude in control $(n=6)$ and $\operatorname{LDD}(n=13)$ recordings. Time of -5 min refers to the time befor TD racorran on tetanus frequency $\left(5-50 \mathrm{~Hz}, 20 \mathrm{~s} ; 0.4 \mathrm{~mm} \mathrm{Ca}^{2+}\right) . n=4,4,4,4,6,4,4$ for the tetanus frequency of $0,5,10,20,30,40,50$ respectively. $\boldsymbol{E}$, Dependency of LTD on $\mathrm{Ca}^{2+}$ concentrations $(0.2-1 \mathrm{~mm}, 30 \mathrm{~Hz}$ for $20 \mathrm{~s}) . n=4,4,4,4,6,4,4$ for no tetanus and 0 , $0.2,0.4,0.7,1.0 \mathrm{~mm} \mathrm{Ca}^{2+}$, respectively. For Figures 1,2 , and 4-7, all recordings were performed on $\mathrm{M} 12$ in segment 3-5 and at

term facilitation (STF) and posttetanic potentiation are detailed in the figure legends. Current signals were amplified with an Axoclamp 2A amplifier (Molecular Devices, Palo Alto, CA). The signals were filtered at $0.1 \mathrm{kHz}$ on-line and converted to a digital signal using a Digidata $1320 \mathrm{~A}$ interface (Molecular Devices), acquired by pClamp 8.0 software (Molecular Devices). Stimulation of nerves was achieved by a Grass Instruments (Quincy, MA) S88 Stimulator. Pressure injection of glutamate (100 mM) was performed using Picosprizter II (General Valve, Fairfield, NJ).

Data analyses and statistics. Evoked and spontaneous responses were analyzed using the Mini Analysis Program (Synaptosoft, Decatur, GA). For continuous long-term recordings, amplitude of each EJC was normalized to the average EJC amplitude before the tetanus. Each time point represents average from three (before tetanus) or six (after tetanus) consecutive EJCs. For analysis of miniature EJCs (mEJCs), continuous recordings of $1 \mathrm{~min}$ (the first $1 \mathrm{~min}$ ) in each $5 \mathrm{~min}$ period were taken for analysis. Quantal amplitude (quantal size) was determined using either the "Gaussian" (for a single peak) or the "10 Simplex" fitting functions in the Origin program (Microcal, Southampton, MA). For each recording, values of average mEJC amplitude and quantal content were normalized to that before tetanus. Quantal content are calculated as dividing average EJC amplitudes by quantal amplitude. Other details of data analysis are described in the figure legends. 


\section{Results}

Induction of LTD

EJCs were recorded from the longitudinal muscle fiber 12 (M12) (for nomenclature, see Johansen et al., 1989a,b; Vactor et al., 1993), which has been examined extensively in physiological studies (Zhong and Wu, 1991; Davis et al., 1998; Rohrbough et al., 1999, 2000; Sigrist et al., 2000). Continuous recordings were made while the segmental nerves innervating the corresponding muscle cells were stimulated using a baseline stimulation frequency of $0.05 \mathrm{~Hz}$. We sought to induce long-term synaptic plasticity by delivering various patterns of tetanic stimulation after $\sim 5$ min of baseline stimulation. LTD was consistently induced by $30 \mathrm{~Hz}$ tetanus for $20 \mathrm{~s}$ at $0.4 \mathrm{~mm}$ external $\mathrm{Ca}^{2+}$ concentration (Fig. 1A-C). It is important to monitor synaptic responses for synaptic failures during the tetanic stimulation that might occur in some preparations, which would then lead to attenuated LTD. In this study, muscle fibers with failures of evoked responses during tetanus $(\sim 20 \%)$ were not included for analysis. We have been able to maintain stable recording for a maximum of $60 \mathrm{~min}$ after LTD induction; LTD persisted throughout the recording period. However, some preparations became unstable after 45 min of recordings, i.e., leakage currents were increased dramatically. We therefore only present data herein recorded within 30 min after tetanus.

In muscle fibers not subjected to high-frequency stimulation, the EJC amplitude also decayed slightly after a long period of recordings (Fig. $1 A, B$ ) but to a much lesser extent than that after LTD induction. The most likely explanation for this decay is a reduction in the quantal amplitude [quantal size (presented later in Fig. $4 A, C)$ ], which is consistent with a previous report of the reduced quantal size after extended period of recording at the Drosophila NMJ (Davis et al., 1998). After accounting for the reduced quantal size, we determined that the quantal contents ( $\mathrm{di}$ viding EJC amplitude by quantal amplitude), in fact, were not changed significantly during the course of recording in the controls (Fig. 1C).

\section{Stimulus frequency and $\mathrm{Ca}^{2+}$ concentration dependence of LTD}

The frequency of tetanic stimulation is critical for induction of LTD. We examined a series of stimulation frequencies, each with duration of $20 \mathrm{~s}$. LTD was not observed after stimulation at 5 or $10 \mathrm{~Hz}$ but was induced after $20 \mathrm{~Hz}$ stimulation. The level of LTD reached a plateau at $30 \mathrm{~Hz}$, and similar levels of LTD were observed at higher frequencies, such as 40 or $50 \mathrm{~Hz}$ (Fig. $1 D$ ). We also examined $10 \mathrm{~Hz}$ stimulation for $60 \mathrm{~s}$, which delivers an equal number of stimuli as does $30 \mathrm{~Hz}$ stimulation for $20 \mathrm{~s}$. This prolonged $10 \mathrm{~Hz}$ stimulation, however, did not elicit LTD (data not shown). Thus, it is the stimulation frequency rather than the total number of stimulation that is crucial for induction of LTD.

External $\mathrm{Ca}^{2+}$ concentration is another critical factor for LTD induction. In the absence of external $\mathrm{Ca}^{2+}$ (the saline was replaced with $\mathrm{Ca}^{2+}$-free saline during the tetanic stimulation), 30 $\mathrm{Hz}$ stimulation failed to elicit LTD (Fig. 1 E). At the range of $0.2-1$ $\mathrm{mm}\left[\mathrm{Ca}^{2+}\right]$, however, the level of LTD was inversely related to the $\mathrm{Ca}^{2+}$ concentrations (Fig. $1 \mathrm{E}$ ). LTD was most pronounced at 0.2 $\mathrm{mM} \mathrm{Ca}^{2+}$, lesser at $0.4 \mathrm{~mm}$, and further reduced at $0.7 \mathrm{~mm}$. At 1 $\mathrm{mM}$, only a shorter form of depression (lasting for $\sim 10 \mathrm{~min}$ ) was observed. These data suggest that relatively low levels of $\mathrm{Ca}^{2+}$ are essential for induction of LTD, whereas higher levels appear to impede LTD induction.

Next we examined whether muscle contraction would disrupt
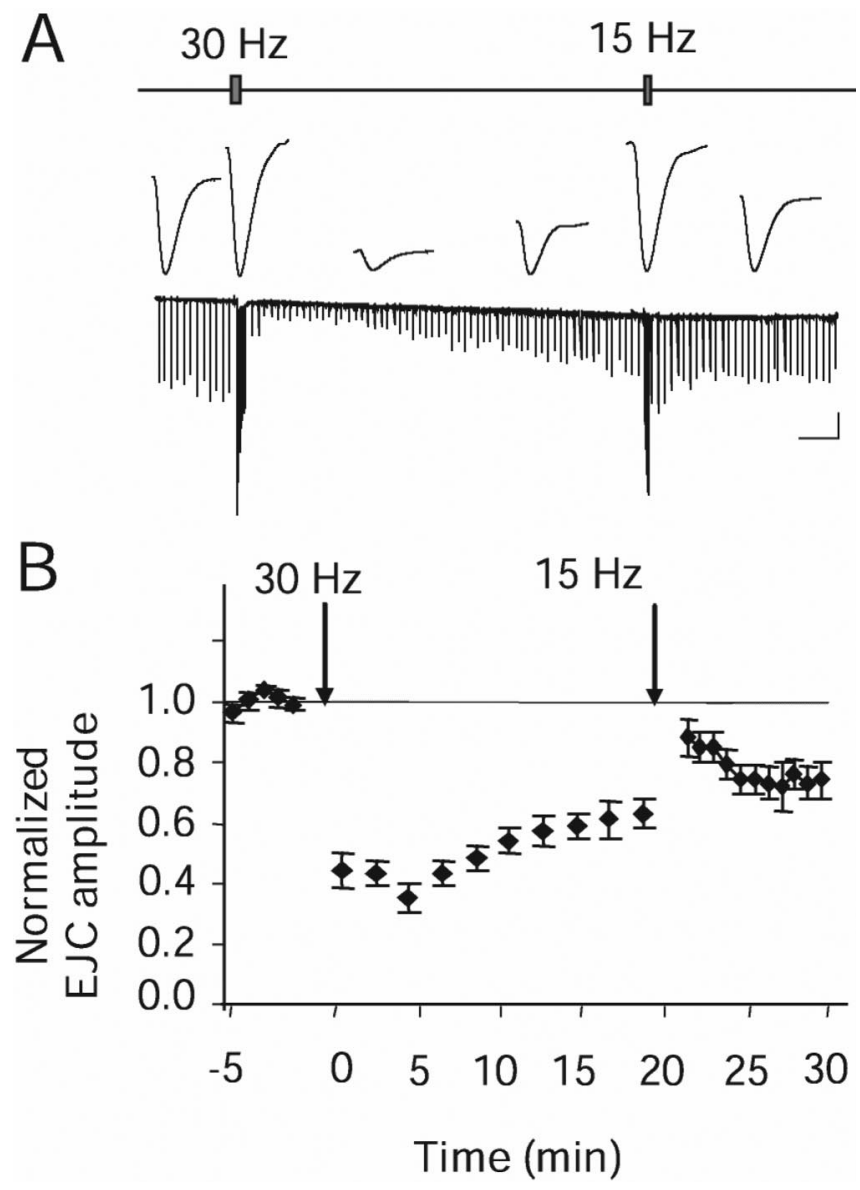

Figure 2. An experiment indicating normal NMJ function after the induction of $L T D$. Tetanus of $15 \mathrm{~Hz}(15 \mathrm{~s})$ was delivered at $20 \mathrm{~min}$ after LTD induction $(30 \mathrm{~Hz}, 20 \mathrm{~s})$; it induced short-term facilitation, posttetanic potentiation, and partial reversal of LTD. $A$, Representative traces. Calibration: $20 \mathrm{nA}, 2 \mathrm{~min}$. $\boldsymbol{B}$, Summary $(n=5)$. Arrows indicate the delivery of 30 and $15 \mathrm{~Hz}$ tetanus.

the functions of the synaptic terminals, which might mimic LTD. To test the functions of the NMJ after the induction of LTD, we delivered $15 \mathrm{~Hz}(15 \mathrm{~s}$ ) stimulation to the depressed nerve terminals at $20 \mathrm{~min}$ after the $30 \mathrm{~Hz}$ stimulation. The NMJ was able to respond to this novel tetanus without failure of transmission and exhibited STF and posttetanic potentiation like the normal NMJ. Moreover, the depression was partially reversed by the $15 \mathrm{~Hz}$ stimulation (Fig. 2). These results suggest that muscle contraction resulting from the induction of LTD did not disrupt NMJ function.

\section{Induction of LTD at different NMJs}

We investigated whether LTD can be induced in muscle fibers other than M12. In each hemisegment, there are 30 individual muscle fibers, each being innervated by multiple motor nerve terminals (Johansen et al., 1989a,b; Kurdyak et al., 1994; Keshishian et al., 1996; Lnenicka and Keshishian, 2000). In addition to M12, we examined M4 and M6, which have also been frequently studied. LTD was also observed at M4 and M6 (Fig. $3 A, B$ ), but the dynamics of depression were different. There appear to be two components of depression in M12, consisting of LTD and a short-term depression (STD) that lasts for $\sim 10 \mathrm{~min}$. In contrast, this short-term depression is absent from M4 and M6, although similar levels of LTD were observed at these fibers. These data suggest that LTD can be 

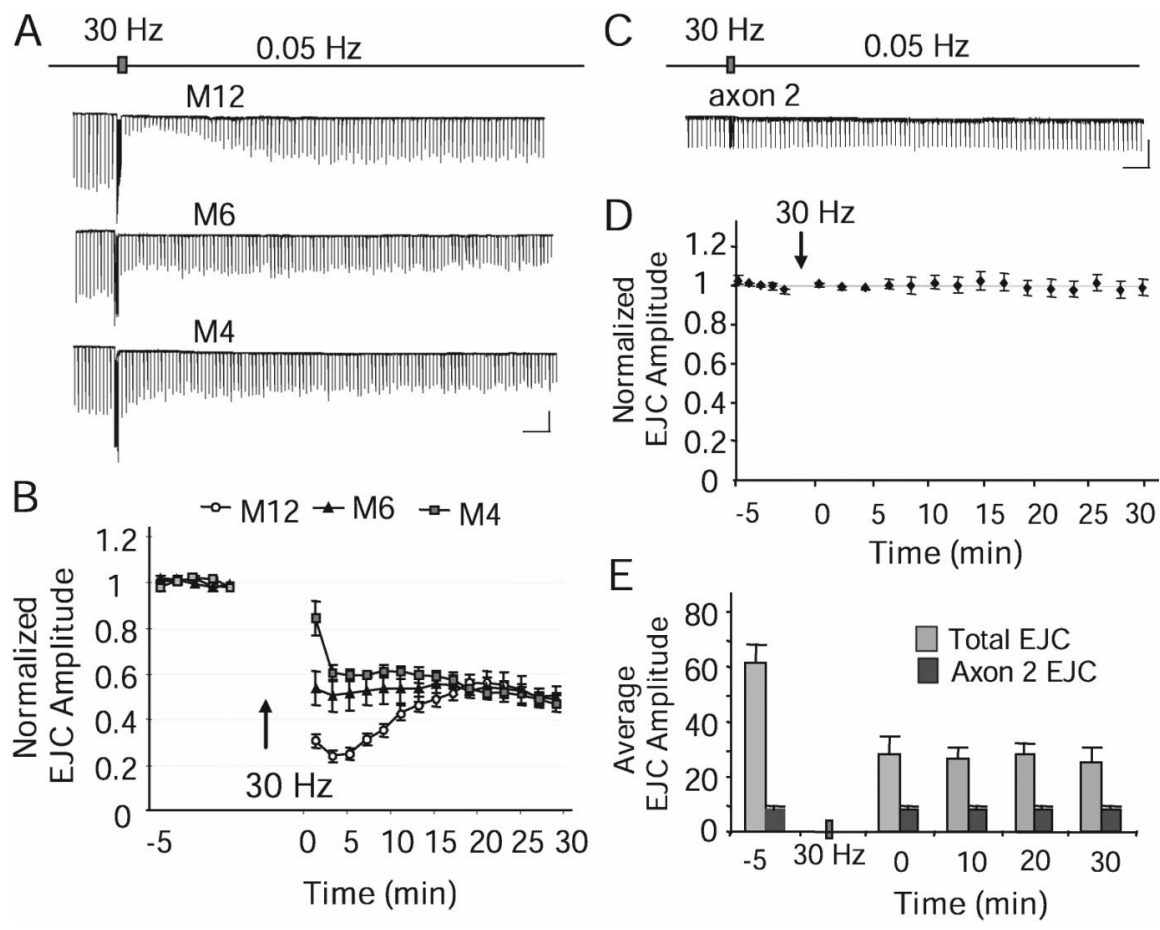

Figure 3. Induction of $L T D$ at various longitudinal muscle fibers $M 4, M 6$, and $M 12(\boldsymbol{A}, \boldsymbol{B})$ and at different axons $(\boldsymbol{C}-\boldsymbol{E})$. $\boldsymbol{A}$ Representative traces. Calibration: $20 \mathrm{nA}, 2$ min. B, Summary of normalized EJC amplitude. $n=4,6,4$ for M4, M6, M12, respectively. $C$, A representative recording on $M 6$ by retrograde stimulation of axon 2 on the nerve branch to M12. Calibration: 10 $\mathrm{nA}, 2 \mathrm{~min}$. D, Summary of experiments on stimulating axon $2 . n=4$. $E$, Comparison of the responses on M6 evoked by stimulating axon 2 and the total EJC evoked by stimulating the segmental nerve. Note that the total EIC amplitudes of the segmental nerve were larger than those of axon 2 after induction of LTD, suggesting that both axons were responsive after LTD induction. $n=4$ for either group.

induced at different muscle fibers, although with different dynamics.

Because each muscle fiber is innervated by multiple axons, we asked whether the high-frequency stimulation caused failure of synaptic transmission in individual axons innervating the same muscle fiber. If this were the case, the observed LTDlike phenomenon would be a result of an inability to generate action potentials from one or more axons rather than depression of synaptic transmission. To investigate this possibility, we took advantage of different innervating patterns of M6 and M12: M6 is innervated by axons 1 and 2, whereas M12 is innervated by axon 2 but not axon 1 (Kurdyak et al., 1994; Lnenicka and Keshishian, 2000). Stimulating the nerve branch innervating M12 allows retrograde stimulation of only axon 2 and recording of its corresponding synaptic responses (EJCs) at M6. The corresponding EJCs were small and highly stable, without depression after the $30 \mathrm{~Hz}$ stimulation (Fig. 3C,D). In contrast, the total EJCs in response to stimulation of the segmental nerve (including both axons 1 and 2) were depressed after the $30 \mathrm{~Hz}$ stimulation but were significantly larger than EJCs evoked by stimulating axon 2 alone (Fig. 3E). Thus, both axon 1 and axon 2 were responsive after the induction of LTD. These observations suggest that LTD did not result from a failure to generate action potentials from either axon.

\section{Presynaptic mechanism}

We then analyzed whether LTD was of presynaptic or postsynaptic origin. First, we performed quantal analysis. In the control without delivery of tetanic stimulation, the quantal amplitude (quantal size, usually representing postsynaptic properties) de- creased gradually with time (Fig. $4 A, C$ ). This decrease accounts for the gradual decay in EJC amplitude in the control (Fig. 1). After LTD induction, the quantal amplitude remained very similar to that before the induction of LTD (Fig. $4 B, D$ ), whereas the quantal content (reflecting the number of vesicles in each EJC) decreased correspondingly to the depression of EJCs (Fig. 1C). The frequency of mEJCs was significantly increased after LTD induction compared with the control (Fig. $4 E$ ), also suggesting there were presynaptic changes. Second, we determined whether the tetanic stimulation altered the muscle responses to exogenously applied glutamate, which is independent from transmitter release from the presynaptic compartment and therefore reflects only changes in postsynaptic properties. The currents induced by the locally perfused glutamate were not significantly different before and after LTD induction (Fig. $4 F$ ). Together, both the results of quantal analysis and the experiment of exogenous glutamate application indicate that LTD is likely a result of presynaptic changes (e.g., a reduced number of vesicles in each evoked response) rather than postsynaptic changes (e.g., the number or sensitivity of the glutamate receptors).

\section{Disruption of LTD in akt mutants}

Subsequent to the identification of LTD in normal flies, we conducted a specific genetic analysis to investigate the underlying molecular mechanisms. It is well known that signal transduction pathways are essential for synaptic plasticity, and synaptic plasticity is closely related to behavioral plasticity. We therefore examined LTD in a variety of mutants that exhibit impaired learning, abnormal synaptic function, or dysregulated signal transduction, such as rutabaga, dunce (Byers et al., 1981; Zhong and Wu, 1991; Levin et al., 1992), latheo (Rohrbough et al., 1999), notch (Ge et al., 2004; Presente et al., 2004; Costa et al., 2005), gap1 [expressing a mutated Rasspecific GTPase-activating protein (Gaul et al., 1992)], and akt (with mutations in the gene encoding the protein kinase B/Akt).

LTD was not significantly affected in most of these mutants, including those that disrupt synaptic transmission or short-term synaptic plasticity (e.g., rutabaga, dunce, and latheo) (Fig. 5B). In contrast, LTD was strongly impaired in the viable akt mutant alleles $a k t^{4226}$ and $a k t^{4226} / a k t^{1}$ (Fig. 5A). The hypomorphic allele $a k t^{4226}$ harbors a P-element insertion upstream of the dakt gene and was reported to cause reduced expression of akt (Spradling et al., 1999; Gao et al., 2000; Stocker et al., 2002), whereas $a k t^{1}$ is an ethylmethyl sulfonateinduced null allele (embryonic lethal) because of a point mutation, dAktF327I, that confers a catalytically inactive kinase (Staveley et al., 1998; Stocker et al., 2002).

We next asked whether the impaired LTD in the akt mutant is attributable to altered dependency on $\mathrm{Ca}^{2+}$ concentration and tetanus frequency. Because LTD was most pronounced at $0.2 \mathrm{~mm}$ $\mathrm{Ca}^{2+}$, we examined LTD in $a k t^{4226}$ using this concentration. LTD 
was similarly disrupted in the akt mutant in $0.2 \mathrm{mM} \mathrm{Ca}^{2+}$ saline as in $0.4 \mathrm{mM} \mathrm{Ca}^{2+}$ saline (Fig. $6 A, B$ ). We also tested whether higher-frequency stimulation $(40 \mathrm{~Hz})$ would overcome the deficit in LTD in the akt mutant; however, this was not the case either (Fig. 6C,D). These data suggest that impaired LTD in the akt mutant is not a result of altered dependency on $\mathrm{Ca}^{2+}$ concentration or stimulation frequency.

LTD was similarly disrupted in the trans-heterozygous allele $a k t^{4226} / a k t^{1}$ as in $a k t^{4226}$. However, $a k t^{1}$ is a null allele whereas $a k t^{4226}$ is hypomorphic, so the trans-heterozygous allele should have less residual akt expression or activity than $a k t^{4226}$. We therefore examined LTD in the heterozygous $a k t^{1} /+$ to test the dose requirement of Akt for LTD. LTD in $a k t^{1} /+$ was not significantly different from that in the wild type (data not shown), suggesting that LTD is normal when the level of Akt is reduced by half. The $a k t^{4226}$ mutant allele is semilethal (only a few homozygous flies survive), homozygous female sterile, and has smaller body size; these phenotypes are also not present in $a k t^{1} /+$. These observations suggest that $a k t^{4226}$ is a strong akt mutant allele. Thus, $a k t^{4226}$ and $a k t^{4226} / a k t^{1}$ may possess similar levels of residual Akt expression or activity and therefore confer similar disruption of LTD. However, it is also possible that the reduction of akt expression in $a k t^{4226}$ is sufficient to produce maximum disruption of LTD.

\section{Rescue of LTD in akt mutants by} induced expression of $a k t$ transgene The impaired LTD in the akt mutants may be because that Akt is directly required to mediate LTD or because of developmental abnormalities. To distinguish between these possibilities, we tested whether the impaired LTD in akt mutants can be rescued by acutely induced expression of a normal akt transgene driven by the promoter of heat shock protein 70 (hsp70-akt) (Scanga et al., 2000). The $a k t^{1}$ mutant carrying $h s p 70-a k t\left(h s p 70-a k t ; a k t^{l}\right)$ is a lethal allele and is therefore maintained over the third multiply inverted TM6 balancer chromosome (with the marker tubby). However, the lethality can be overcome by daily $\mathrm{HS}$ treatment $\left(37^{\circ} \mathrm{C}, 30\right.$ min; see Materials and Methods) to induce the expression of hsp70-akt from embryonic stage (Scanga et al., 2000). Thus, we were able to examine LTD in the larvae of $h s p 70$-akt;akt ${ }^{1}$.

To examine hsp70-akt;akt ${ }^{1}$ as an akt mutant for control purpose, it is necessary to silence or minimize the expression of the $h s p 70$-akt transgene. The allele $h s p 70$-akt;akt ${ }^{1}$ would be a null akt mutant allele if the expression of transgene could be completely silenced. There are several sources of leaky or residual expression of the akt transgene. First, there may be residual expression after the daily heat shock exposure. Sec-
B

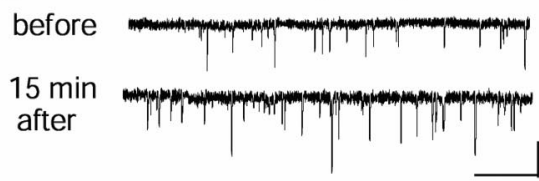

$\mathrm{D}$

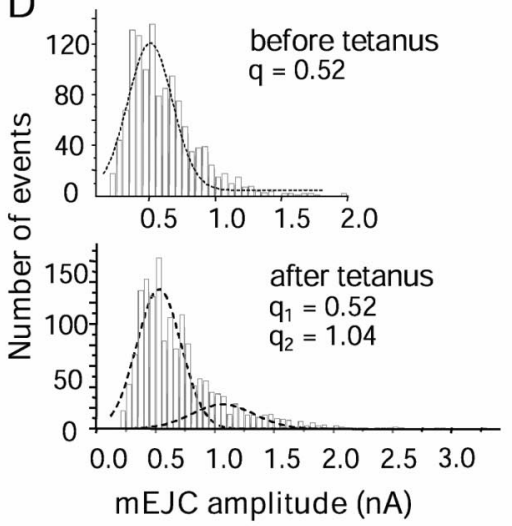

F

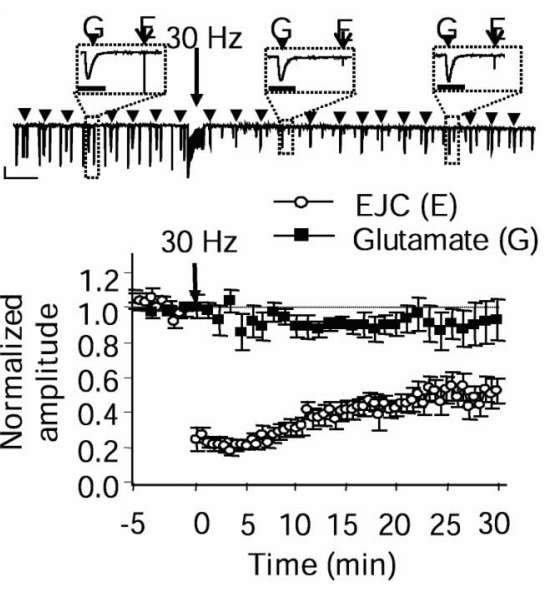

Figure 4. Analysis of mEJCs and local glutamate perfusion-induced currents. Changes of mEJCs in the control $(A, C, E)$ and before and after LTD induction $(\boldsymbol{B}, \boldsymbol{D}, \boldsymbol{E}) . \boldsymbol{A}, \boldsymbol{B}$, Representative mEJC traces. $\boldsymbol{C}, \boldsymbol{D}$, Histogram and Gaussian fitting of mEJCs. $\boldsymbol{E}$, S induction (15 min), quantal size remained unchanged, but there was an increased number of larger events that form a second peak, suggesting two quantal releases (D). As a result, the total frequency of $\mathrm{mEJC}$ also increased after the tetanus compared with not significantly change after the induction of LTD. Top, Representative traces. Arrowheads indicate the glutamate-induced currents ("G"), which have slow kinetics; all other fast spikes are EJCs ("E"). Calibration: $20 \mathrm{nA}, 1 \mathrm{~min}$. Expanded traces before and after the $30 \mathrm{~Hz}$ tetanus are shown in the boxes (scale bars, $100 \mathrm{~ms}$ ). Bottom, Summary. $n=6$.

ond, the hsp70 promoter may be leaky at room temperature. Third, we observed a few first-instar larvae homozygous for $a k t^{1}$ in $h s p 70-a k t ; a k t^{1}$ even when the animals were raised at $18^{\circ} \mathrm{C}$ and were not exposed to heat shock, suggesting that there is a small amount of leaky expression of hsp70-akt. Apparently, such leaky expression is unrelated to the hsp70 promoter, but is possibly attributable to local genomic enhancer(s) or promoter (s), and therefore cannot be eliminated by temperature adjustment. This small leaky expression prevented us from examining a null akt mutant allele. To minimize the leaky or residual hsp70-akt expression as a result of the hsp70 promoter, we shifted the larvae homozygous for $a k t^{1}$ in $h s p 70-a k t 1 ; a k t^{1}$ (rescued by daily heat shock treatment) from $\mathrm{RT}$ to $18^{\circ} \mathrm{C}$ for $24-36 \mathrm{~h}$ after the last daily heat shock exposure.

We then tested whether impaired LTD in akt mutants can be 

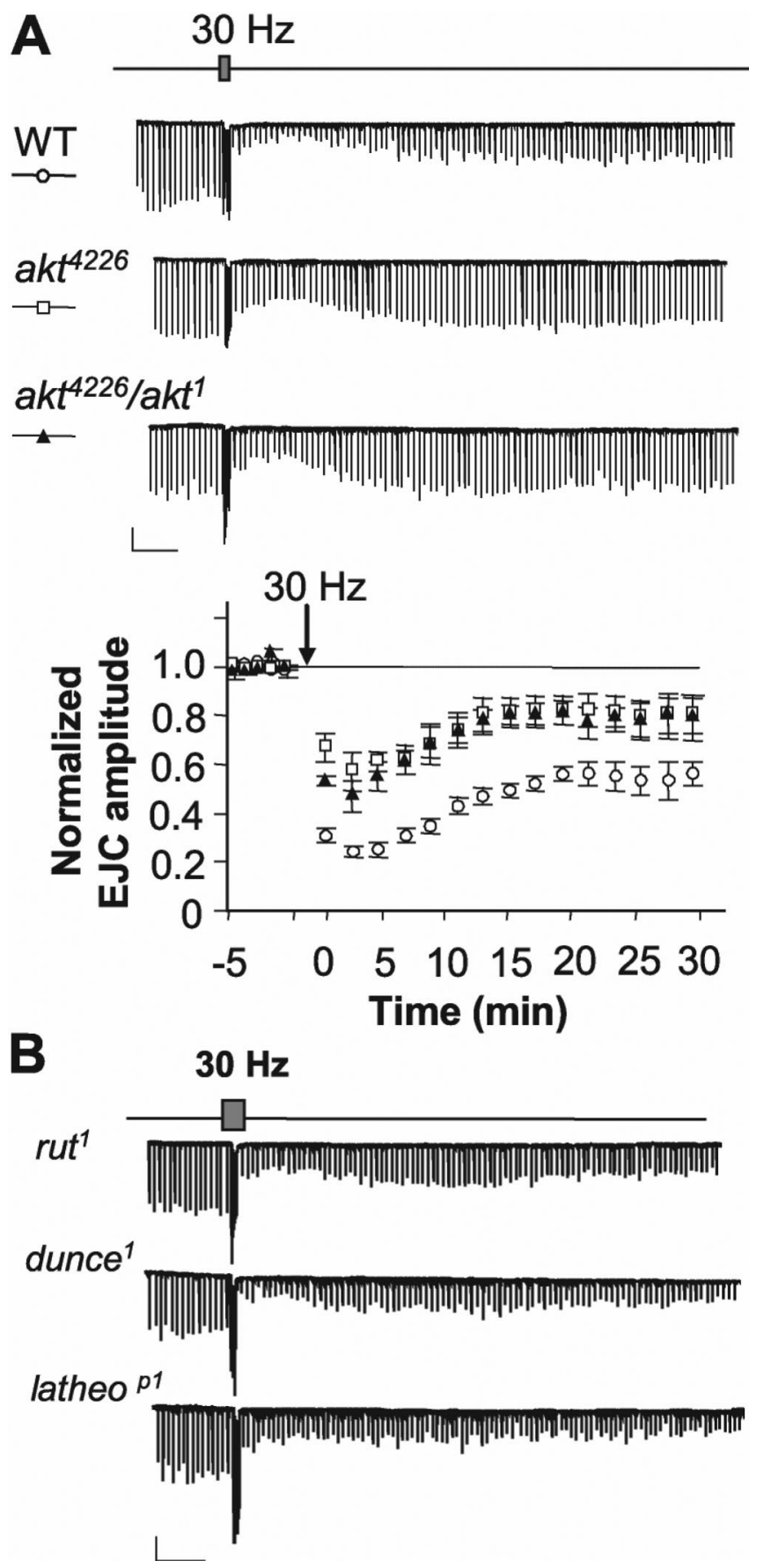

Figure 5. LTD was primarily reduced in the akt mutant alleles $a k t^{4226}$ and $a k t^{4226} / a k t^{7}(\boldsymbol{A})$ but not affected in the mutants of rutabaga, dunce, and latheo $(\boldsymbol{B}) . \boldsymbol{A}$, Representative recordings (top) (calibration: $20 \mathrm{nA}, 2 \mathrm{~min}$ ) and summary of normalized EJC amplitude (bottom) in control and akt mutant alleles. WT, Wild type. $\boldsymbol{B}$, Representative LTD recordings in the mutants of rutabaga $\left(\right.$ rut $\left.^{T}\right)$, dunce $\left(\right.$ dunce $\left.{ }^{7}\right)$, and latheo $\left(\right.$ latheo $\left.{ }^{P 7}\right)$.

rescued by acutely induced expression of hsp70-akt. The hsp70$a k t 1 ; a k t^{1}$ larvae (homozygous for $a k t^{1}$ ) from $18^{\circ} \mathrm{C}$ were examined for LTD either directly or after additional heat shock treatment (for heat shock paradigm, see below and Materials and Methods). Without additional heat shock, these larvae exhibited impaired LTD as did the larvae of the other akt mutants (Fig. $7 A, 18^{\circ} \mathrm{C}$ ), suggesting that $h s p 70$-akt1;akt (homozygous for $a k t^{1} ; 18^{\circ} \mathrm{C}$ ) is an akt mutant allele and that shifting to $18^{\circ} \mathrm{C}$ effectively reduced the leaky expression of $h s p 70$-akt. After additional heat shock treatment $\left(37^{\circ} \mathrm{C}\right.$, two times for $15 \mathrm{~min}, 2 \mathrm{~h}$ interval; see Materials and
Methods), the impaired LTD in hsp70-akt1;akt larvae $\left(18^{\circ} \mathrm{C}\right)$ was fully rescued (Fig. $7 A, 18^{\circ} \mathrm{C} \rightarrow \mathrm{HS}$ ). As a control, the same heat shock paradigm did not produce any effect on $a k t^{4226}$ (data not shown), suggesting that the rescue effect is specifically attributable to $h s p 70$-akt expression. These result indicate that acutely induced $h s p 70$-akt expression was able to rescue the defective LTD in $a k t^{1}$ mutant.

We then examined whether impaired LTD in $a k t^{4226} / a k t^{1}$ can also be rescued by transiently induced expression of hsp70-akt. We crossed the $h s p 70$-akt;akt with $a k t^{4226}$; therefore, there is one copy of $h s p 70$-akt transgene in this allele. These larvae were viable at room temperature without heat shock treatment and showed impaired LTD like the other mutant alleles (Fig. 7B). Again, the impaired LTD in this allele was rescued by heat shock treatment $\left(37^{\circ} \mathrm{C}\right.$, two to four times for $15 \mathrm{~min}, 1.5-2 \mathrm{~h}$ interval) (Fig. $7 \mathrm{~B}$ ). Thus, transiently induced expression of $h s p 70$-akt was able to rescue impaired LTD in two akt mutant alleles, indicating that Akt is directly required to mediate LTD.

The degree of LTD rescue appears to be proportional to the amount of $h s p 70$-akt expression. The $h s p 70$-akt;akt larvae at RT exhibited partial rescue of LTD (examined at $24 \mathrm{~h}$ after the last daily HS), although with considerable variance, whereas they showed complete rescue shortly after additional heat shock treatment (two times for $15 \mathrm{~min}, 37^{\circ} \mathrm{C}, 2 \mathrm{~h}$ interval) (Fig. 7C). Similarly, the impaired LTD in hsp70-akt; akt $t^{4226}$ / $a k t^{1}$ larvae was partially rescued after two exposures of heat shock $\left(15 \mathrm{~min}, 37^{\circ} \mathrm{C}, 2 \mathrm{~h}\right.$ interval) but fully rescued after four exposures of heat shock $\left(15 \mathrm{~min}, 37^{\circ} \mathrm{C}, 1.5-2 \mathrm{~h}\right.$ interval; $p<$ 0.01 ) (Fig. $7 D$ ). These data further underscore the essential role of Akt for LTD.

\section{Normal synaptic transmission and short-term synaptic plasticity in akt mutants}

Drosophila NMJ exhibits multiple forms of short-term plasticity (Jan and Jan, 1978; Zhong and Wu, 1991; Broadie et al., 1997). To determine whether the impaired LTD in the akt mutants is a result of defective synaptic transmission or abnormal short-term synaptic plasticity, we examined spontaneous and evoked synaptic transmission, short-term facilitation, and posttetanic potentiation in the akt mutants. The amplitude and frequency of mEJC (Fig. 8A,B) and the amplitude and calcium dependency of EJCs (Fig. 8C,D) in $a k t^{4226}$ and $a k t^{4226} / a k t^{1}$ are indistinguishable from those in the wild type. Similarly, short-term facilitation within the pulse train (Fig. $8 E$ ), the frequency dependence of short-term facilitation (Fig. $8 \mathrm{~F}$ ), and posttetanic potentiation (Fig. $8 \mathrm{G}$ ) were also normal in the akt mutants. These data suggest that Akt is not essential for basic synaptic transmission and short-term plasticity.

\section{Akt expression at the NMJ}

We examined whether Akt is expressed at the Drosophila NMJ. We stained the NMJs of third-instar larvae using a polyclonal antibody against Drosophila Akt (Staveley et al., 1998) and observed strong dAkt-like immunoreactivity at the NMJ (Fig. 9). Consistent with previous studies (Spradling et al., 1999; Gao et al., 2000; Stocker et al., 2002), the dAkt staining is reduced in $a k t^{4226}$, as shown in both the synaptic boutons and the nerve branches (Fig. 9). The staining intensity measured in the synaptic boutons of $a k t^{4226}$ was also significantly reduced compared with the wild type (wild type, $114.8 \pm 3.1 ; a k t^{4226}, 73.1 \pm 3.1 ; p<$ 0.01 ). These results indicate that Akt is expressed at the Drosophila NMJ. 


\section{Discussion}

In the current work, we explored conditions for inducing LTD at the Drosophila larval NMJ and characterized the properties of LTD. LTD is dependent on the stimulation frequency and $\mathrm{Ca}^{2+}$ concentration and can be induced in various muscle fibers that are differentially innervated. Several observations indicate that the depression depends on synaptic transmission but not muscle contraction. First, after LTD induction, the NMJ responded normally to high-frequency stimulation and showed normal short-term synaptic plasticity, such as short-term facilitation and posttetanic potentiation (Fig. 2), and partial reversal of LTD from the novel stimulation $(15 \mathrm{~Hz})$. Second, LTD was attenuated at increased external $\mathrm{Ca}^{2+}$ concentrations when muscle contraction was more severe. Furthermore, LTD was disrupted in the akt mutants and rescued by acutely induced expression of the normal akt transgene.

The properties of LTD described here are similar to LTD reported previously in different preparations. For example, a major feature for LTD is the requirement of the presence of external $\mathrm{Ca}^{2+}$, but its formation is also prevented if intracellular accumulation of $\mathrm{Ca}^{2+}$ is too high (Ito, 1989; Gall et al., 2005). Similarly, LTD at the Drosophila NMJ failed in the absence of $\mathrm{Ca}^{2+}$ but was most pronounced at relatively low $(0.2$ $\mathrm{mm}$ ) external $\mathrm{Ca}^{2+}$ and attenuated with increasing $\mathrm{Ca}^{2+}$ concentrations. In other synaptic preparations, a long period of lowfrequency stimulation (e.g., $1 \mathrm{~Hz}$ for $15 \mathrm{~min}$ ) was typically used to induce LTD, albeit at high external $\mathrm{Ca}^{2+}$ concentrations. Although we used relatively high frequency stimulation $(30 \mathrm{~Hz})$, the relatively low external $\mathrm{Ca}^{2+}$ concentrations would limit $\mathrm{Ca}^{2+}$ influx; thus, similar internal $\mathrm{Ca}^{2+}$ concentrations may have been achieved in LTD induction at the Drosophila NMJ and other synapses. Our finding of a requirement of Akt for LTD also agrees with the report that the phosphatidylinositol 3 (PI-3) kinase/Akt/target of rapamycin (TOR) signaling is required for LTD in the hippocampus (Hou and Klann, 2004), although the role of Akt was not directly examined.

LTD in mammals can be divided into NMDA and nonNMDA receptor dependent and can be expressed at either the presynaptic site via a reduction in release probability or the postsynaptic site involving a decrease in AMPA receptor via clathrin-mediated endocytosis (Anwyl, 2006). It remains to be determined whether Drosophila LTD is NMDA or non-NMDA receptor dependent. However, our analyses indicate that Drosophila LTD is mainly expressed at the presynaptic site; therefore, it should not involve regulation of the number of postsynaptic AMPA receptors.

\section{Short-term depression and LTD}

STD at the Drosophila NMJ occurs during (but not after) highfrequency stimulation (10 Hz or higher) (Zhong and $\mathrm{Wu}$, 1991; Delgado et al., 2000; Renger et al., 2000). Recently, a new type of STD during low-frequency stimulation of $0.5-1 \mathrm{~Hz}$ was reported (Wu et al., 2005). These forms of STD recover soon after termination of the stimulation. We observed similar STD during the high-frequency stimulation that induces LTD, which was not significantly different between the akt mutants and the wild type (data not shown). In addition, we observed a novel form of short-term depression that lasts for 10-15 min after the high-frequency stimulation at M12 but not M4 and M6 (Fig. 1). It is distinct from LTD because it was only elicited by $30 \mathrm{~Hz}$ or higher frequency stimulation but not by $20 \mathrm{~Hz}$ stimulation, which induced similar LTD, and was induced even at $1 \mathrm{mM} \mathrm{Ca}^{2+}$ when LTD was nearly absent (Fig. $1 \mathrm{E}$ ). This short-term depression was also little affected in the akt mutants, in contrast to the disruption of LTD (Fig. 5). Thus, our data indicate that all forms of short-term plasticity are normal in akt mutants. In contrast, the mutants (e.g., dunce, rutabaga, and latheo) that exhibit defective short-term synaptic plasticity displayed normal LTD (Fig. 5B). These observations suggest that the mechanisms of LTD are distinct from those of STD and other forms of short-term synaptic plasticity.

It is believed that depletion of the readily releasable vesicle pool (RRP) is a candidate mechanism for short-term depression (Zucker and Regehr, 2002). A similar RRP and a reserved vesicle pool (RP) have been demonstrated at the Drosophila NMJ (Kuromi and Kidokoro, 2000; Kidokoro et al., 2004). However, two observations suggest that depletion of RRP did not occur after LTD induction. First, LTD was less pronounced at higher $\mathrm{Ca}^{2+}$ concentration (e.g., $1.0 \mathrm{~mm}$ ), at which much more transmitter would have been released. Second, mEJC frequency should be decreased by depletion of RRP (Koenig and Ikeda, 1999; Delgado et al., 2000; Zucker and Regehr, 2002), but it was instead increased after LTD induction.

\section{mEJC frequency and LTD}

Along with LTD, there was increased mEJC frequency, which also appears to be long lasting (Fig. $4 E$ ). The mechanisms of mEJC frequency increase, and its relationship to LTD is not clear. One 
A

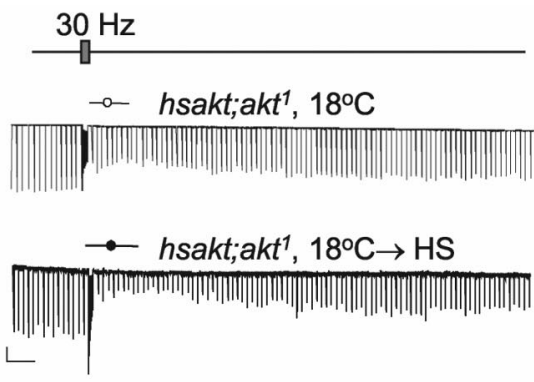

B

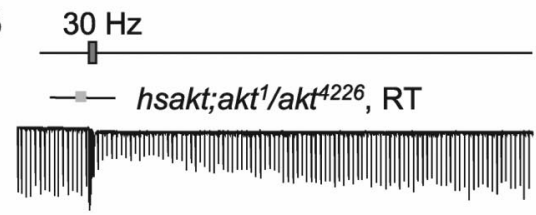

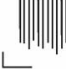

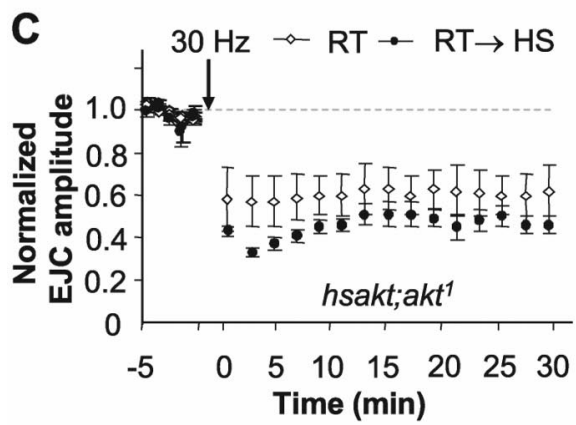

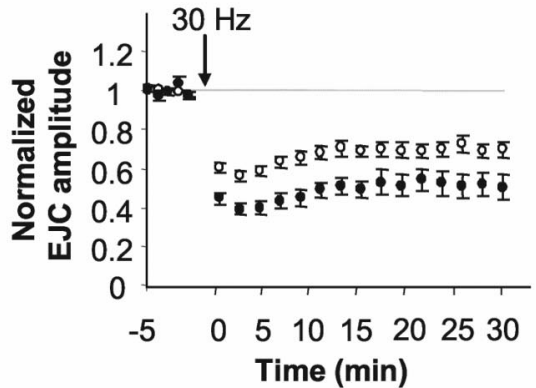

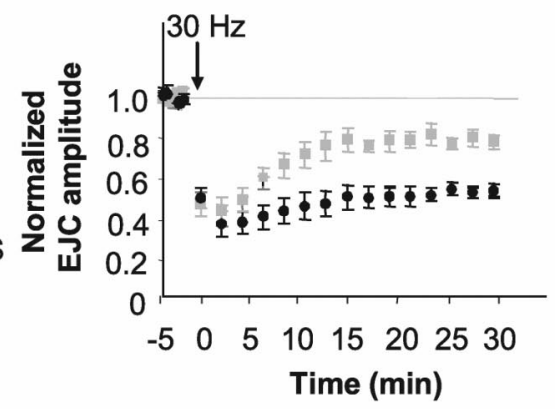

D

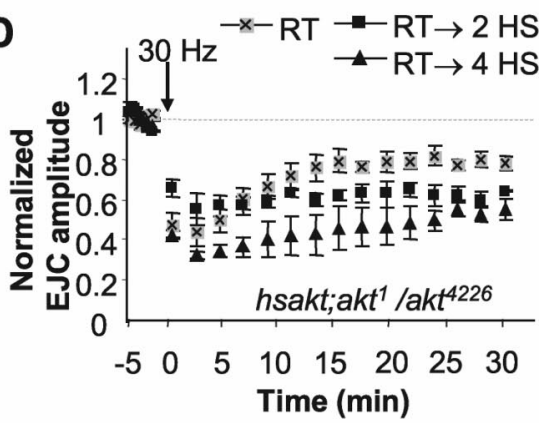

Figure 7. Rescue of LTD in $a k t^{1}$ and $a k t^{4226} / a k t^{7}$ by acutely induced expression of hsp70-akt transgene. The hsp70-akt; akt ${ }^{7}$ embryos and larvae were given developmental daily heat shock exposures to overcome the lethality (see Materials and Methods). $A$, Rescue of LTD in hsp70-akt; akt ${ }^{7}$ after brief heat shock exposures. hsp70-akt; akt ${ }^{7}$ larvae were shifted to $18^{\circ} \mathrm{C}$ for $24-48 \mathrm{~h}$ after the last daily heat shock treatment (hsp70-akt;akt $\left.{ }^{\top}, 18^{\circ} \mathrm{C}\right)$. These larvae showed impaired LTD like the akt mutants ( $p>0.05$ compared with $a k t^{4226}$ and $a k t^{4226} / a k t^{7}$; two-way ANOVA). For acutely inducing $h s p 70$-akt expression, a group of larvae was brought from $18^{\circ} \mathrm{C}$ to $\mathrm{RT}$ for $3-6 \mathrm{~h}$ and then were given heat shocks $\left(18^{\circ} \mathrm{C} \rightarrow \mathrm{HS}\right.$; two heat shock exposures of $15 \mathrm{~min}$ at $37^{\circ} \mathrm{C}, 2 \mathrm{~h}$ interval). $n=14$ and 9 for the groups of $18^{\circ} \mathrm{C}$ and $18^{\circ} \mathrm{C} \rightarrow \mathrm{HS}$, respectively. $\boldsymbol{B}$, Rescue of LTD by acutely induced hsp70-akt expression in the heterozygous allele $a k t^{4226} / a k t^{7}$. The allele $h s p 70-a k t ; a k t^{4226} / a k t^{7}$ at RT showed impaired LTD like the akt mutant (hsp70-akt;akt ${ }^{4226} / a k t^{7}$; RT). The defective LTD was rescued by three to four brief heat shock exposures $\left(37^{\circ} \mathrm{C}, 15 \mathrm{~min}\right.$, $1.5-2 \mathrm{~h}$ intervals) (hsp 70-akt; akt ${ }^{4226} / a k t^{7}, \mathrm{RT} \rightarrow 3-4 \mathrm{HS}$ ). $n=4$ and 6 for the groups RT and RT-HS, respectively. Calibration: 20 $\mathrm{nA}, 2$ min. C, D, Rescue of LTD appears to correlate with the amount of hsp70-akt expression. $C$, In hsp70-akt; akt ${ }^{7}$ larvae, LTD was partially rescued at $\mathrm{RT}$ and fully rescued after additional heat shock exposures ( 2 times for $15 \mathrm{~min}, 37^{\circ} \mathrm{C}, 2 \mathrm{~h}$ interval). $n=4$ and 5 for the RT and RT-HS groups, respectively. $\boldsymbol{D}, \operatorname{In} h s p 70$-akt; akt ${ }^{4226} / a k t^{1}$, impaired LTD was partially rescued after two heat shock exposures $\left(15 \mathrm{~min}, 37^{\circ} \mathrm{C}, 2 \mathrm{~h}\right.$ interval; $n=3$ ) but was fully rescued after four heat shock exposures (see Fig. $\left.6 B ; n=3\right) . n=4$ for the RT group.

candidate mechanism for increased $\mathrm{mEJC}$ frequency is an increase of the number of vesicles in RRP resulting from mobilization of alternative vesicle pools (e.g., RP) (Stevens and Sullivan, 1998; Waters and Smith, 2000; Tyler and Pozzo-Miller, 2001). It was shown that, at relatively high external $\mathrm{Ca}^{2+}$ concentration $(2$ $\mathrm{mm}$ ), prolonged high-frequency stimulation $(30 \mathrm{~Hz}, 30 \mathrm{~s}$ or more) mobilizes the RP via a cAMP/protein kinase A-dependent mechanism (Kuromi and Kidokoro, 2000; Kidokoro et al., 2004). Therefore, mobilization of synaptic vesicles from RP to RRP by the LTD-inducing tetanus may account for the increased mEJC frequency and contribute to evoked synaptic transmission after LTD induction. However, the $\mathrm{Ca}^{2+}$ concentration for LTD induction was much lower and the tetanic stimulation for inducing
LTD was shorter than required to mobilize the RP (Kuromi and Kidokoro, 2000). In addition, disrupting the cAMP signaling in rutabaga and dunce or by an inhibitor of protein kinase A (RP-cAMP; data not shown) did not significantly affect the increased mEJC frequency and LTD. Thus, mobilization of RP may not have occurred after LTD induction.

\section{Akt and LTD}

Akt mediates signaling from numerous growth factors, cytokines, hormones, and neurotransmitters to regulate diverse physiological functions, such as glucose metabolism, cell and organ growth, anti-apoptosis, and cell survival (Brazil and Hemmings, 2001). It also critically regulates neuronal survival (Dudek et al., 1997; Brunet et al., 2001) and the number of neurotransmitter (GABA) receptors (Wang et al., 2003). However, whether Akt mediates longterm synaptic plasticity has not been shown previously. Here we provided evidence that Akt is directly required to mediate LTD but not short-term synaptic plasticity. LTD was disrupted in multiple akt mutant alleles, $a k t^{4226}, a k t^{4226}$, $a k t^{1}$ (Fig. 5), and $h s p 70-a k t$; akt $t^{1}$ at $18^{\circ} \mathrm{C}$ (Fig. 7A), and was rescued by acutely induced expression of hsp70-akt. However, because no akt null allele is available, we are yet unable to address whether LTD would be abolished by complete loss of the Akt protein. It also remains to be determined whether Drosophila LTD is mediated by the same upstream (PI-3 kinase) and downstream (TOR) signaling of Akt as the metabotropic glutamate receptor-dependent LTD in the hippocampus (Hou and Klann, 2004). A few other Akt substrates [Raf, mitogen-activated protein kinase, nitric oxide synthase, and CREB (Brazil and Hemmings, 2001)] were also shown to be involved in LTD induction or expression in vertebrate synapses (Ito, 2001; Thiels et al., 2002); whether these molecules play a role in Drosophila LTD remains to be investigated.

In summary, we have described for the first time long-term synaptic depression at the Drosophila larval NMJ induced by specific high-frequency stimulation, which is directly mediated by Akt. Thus, it is possible to perform genetic analysis of the molecular mechanisms of long-term synaptic plasticity in Drosophila. Given the importance of long-term synaptic plasticity to learning and memory, our findings also suggest a role of Akt in these essential brain functions. Genetic analysis of long-term plasticity in Drosophila would reveal specific molecular events and interactions underlying behavioral plasticity. 


\section{References}

Anwyl R (2006) Induction and expression mechanisms of postsynaptic NMDA receptorindependent homosynaptic long-term depression. Prog Neurobiol 78:17-37.

Brazil DP, Hemmings BA (2001) Ten years of protein kinase B signalling: a hard Akt to follow. Trends Biochem Sci 26:657-664.

Broadie K, Rushton E, Skoulakis EM, Davis RL (1997) Leonardo, a Drosophila 14-3-3 protein involved in learning, regulates presynaptic function. Neuron 19:391-402.

Brunet A, Datta SR, Greenberg ME (2001) Transcription-dependent and -independent control of neuronal survival by the PI3K-Akt signaling pathway. Curr Opin Neurobiol 11:297-305.

Byers D, Davis RL, Kiger Jr JA (1981) Defect in cyclic AMP phosphodiesterase due to the dunce mutation of learning in Drosophila melanogaster. Nature 289:79-81.

Cash S, Dan Y, Poo MM, Zucker R (1996) Postsynaptic elevation of calcium induces persistent depression of developing neuromuscular synapses. Neuron 16:745-754.

Chen CN, Denome S, Davis RL (1986) Molecular analysis of cDNA clones and the corresponding genomic coding sequences of the Drosophila dunce+ gene, the structural gene for cAMP phosphodiesterase. Proc Natl Acad Sci USA 83:9313-9317.

Costa RM, Drew C, Silva AJ (2005) Notch to remember. Trends Neurosci 28:429-435.

Davis GW, DiAntonio A, Petersen SA, Goodman CS (1998) Postsynaptic PKA controls quantal size and reveals a retrograde signal that regulates presynaptic transmitter release in Drosophila. Neuron 20:305-315.

Delgado R, Maureira C, Oliva C, Kidokoro Y, Labarca P (2000) Size of vesicle pools, rates of mobilization, and recycling at neuromuscular synapses of a Drosophila mutant, shibire. Neuron 28:941-953.

DeZazzo J, Sandstrom D, de Belle S, Velinzon K, Smith P, Grady L, DelVecchio M, Ramaswami M, Tully T (2000) nalyot, a mutation of the Drosophila myb-related Adf1 transcription factor, disrupts synapse formation and olfactory memory. Neuron 27:145-158.

Dudek H, Datta SR, Franke TF, Birnbaum MJ, Yao R, Cooper GM, Segal RA, Kaplan DR, Greenberg ME (1997) Regulation of neuronal survival by the serine-threonine protein kinase Akt. Science 275:661-665.

Etherington SJ, Everett AW (2004) Postsynaptic production of nitric oxide implicated in longterm depression at the mature amphibian (Bufo marinus) neuromuscular junction. J Physiol (Lond) 559:507-517.

Feng Y, Ueda A, Wu CF (2004) A modified minimal hemolymph-like solution, HL3.1, for physiological recordings at the neuromuscular junctions of normal and mutant Drosophila larvae. J Neurogenet 18:377-402.

Gall D, Prestori F, Sola E, D’Errico A, Roussel C, Forti L, Rossi P, D’Angelo E (2005) Intracellular calcium regulation by burst discharge determines bidirectional long-term synaptic plasticity at the cerebellum input stage. J Neurosci 25:4813-4822.

Gao X, Neufeld TP, Pan D (2000) Drosophila PTEN regulates cell growth and proliferation through PI3K-dependent and -independent pathways. Dev Biol 221:404-418.

Gaul U, Mardon G, Rubin GM (1992) A putative Ras GTPase activating protein acts as a negative regulator of signaling by the Sevenless receptor tyrosine kinase. Cell 68:1007-1019.
B

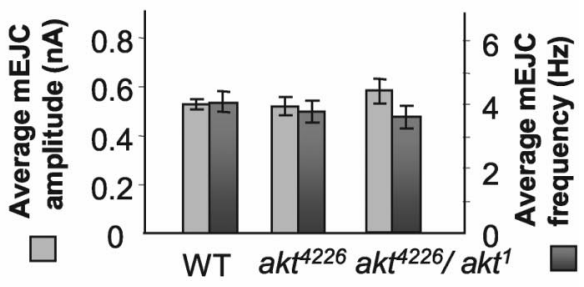

D
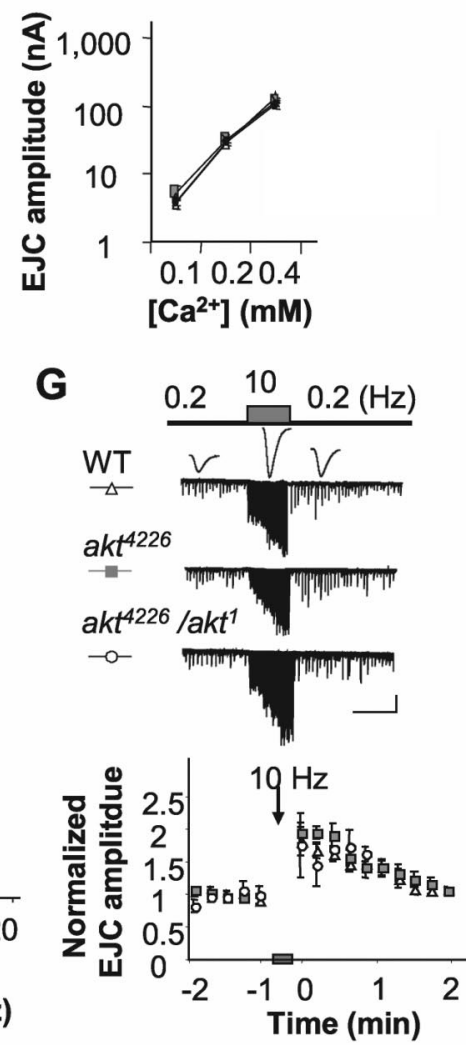

Figure 8. Normal synaptic transmission and short-term plasticity $(\boldsymbol{E}-\boldsymbol{G})$ in the akt mutants $a k t^{4226}$ and $a k t^{4226} / a k t^{1}$. A, Representative traces of spontaneous mEJCs in wild type (WT) and the akt mutants. Calibration: $1 \mathrm{nA}, 1 \mathrm{~s}$. B, Summary of amplitude and frequency of mEJCs. $n=8$ and 6 for WT and akt groups, respectively. C, Representative traces of EJCs at different $\mathrm{Ca}^{2+}$ concentrations $(0.1,0.2$, and $0.4 \mathrm{~mm})$ in wild type and the akt mutants. Calibration: for 0.1 and $0.2 \mathrm{~mm} \mathrm{Ca}{ }^{2+}, 10 \mathrm{nA}, 10 \mathrm{~ms}$; for $0.4 \mathrm{~mm}$ $\mathrm{Ca}^{2+}, 20 \mathrm{nA}, 10 \mathrm{~ms} . \boldsymbol{D}, \mathrm{Ca}^{2+}$ dependency of EJCs: logarithmic plot of the power relationship in the range of $0.1-0.4 \mathrm{~mm} \mathrm{Ca}{ }^{2+}$. $n=6,6$, and 4 for the control (diamond), akt ${ }^{4226}$ (square), and $a k t^{4226} / a k t^{7}$ (triangle) groups, respectively. E, Normal STF during hort train of repetitive stimulation $(25 \mathrm{~Hz})$ in the akt mutants. Top, Representative traces. Bottom, Summary of normalized EJC amplitude. $n=5$ for each group. $\boldsymbol{F}$, Normal dependence of STF on stimulation frequency in the akt mutants. Trains of 20 stimuli were delivered at the frequency of $0.5-20 \mathrm{~Hz}$. The amplitudes of the last 10 responses (EJS) in each train were averaged and ized to the average EJC amplitude at $0.5 \mathrm{~Hz}$. Top, EJC traces representative of the average of last $10 \mathrm{EJCs}$ for 0.5 and $10 \mathrm{~Hz}$. ontinuous recordings were made at $0.2 \mathrm{~Hz}$ stimulation before and after the $10 \mathrm{~Hz}$ tetanus. Top, Representative traces. Calibration $5 \mathrm{nA}, 1 \mathrm{~min}$. Bottom, Summary of normalized EJC amplitudes. $n=11,10$, and 6 for control, akt ${ }^{4226}$, and $a k t^{4226} / a k t^{1}$ groups, respectively. $\left[\mathrm{Ca}^{2+}\right], 0.15 \mathrm{~mm}$ for $\boldsymbol{E}-\mathbf{G}$.

Ge X, Hannan F, Xie Z, Feng C, Tully T, Zhou H, Xie Z, Zhong Y (2004) Notch signaling in Drosophila long-term memory formation. Proc Natl Acad Sci USA 101:10172-10176.

Guo HF, The I, Hannan F, Bernards A, Zhong Y (1997) Requirement of Drosophila NF1 for activation of adenylyl cyclase by PACAP38-like neuropeptides. Science 276:795-798.

Guo HF, Tong J, Hannan F, Luo L, Zhong Y (2000) A neurofibromatosis1-regulated pathway is required for learning in Drosophila. Nature 403:895-898.

Hou L, Klann E (2004) Activation of the phosphoinositide 3-kinase-Aktmammalian target of rapamycin signaling pathway is required for metabotropic glutamate receptor-dependent long-term depression. J Neurosci 24:6352-6361.

Ito M (1989) Long-term depression. Annu Rev Neurosci 12:85-102. 


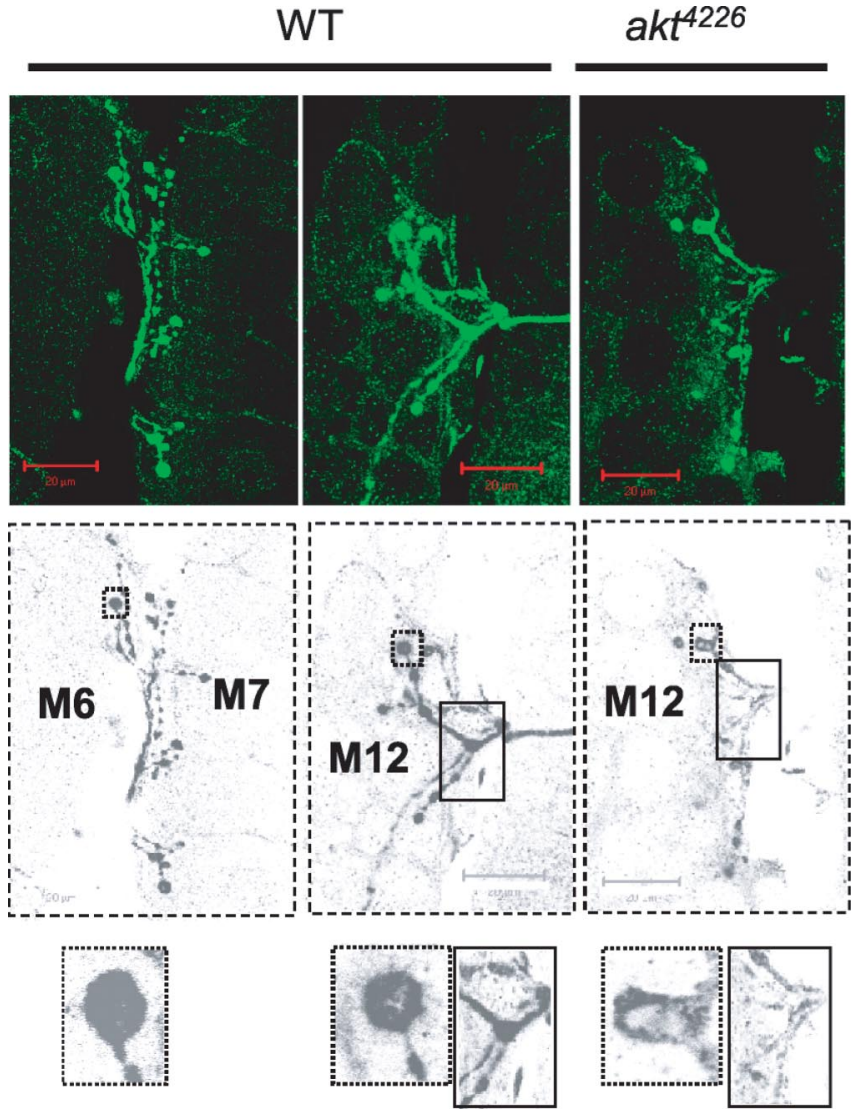

Figure 9. Expression of Akt at the Drosophila NMJ and reduced Akt expression in the hypomorphic akt mutant $a k t^{4226}$. NMJs were stained using a polyclonal anti-dAkt antibody and FITC-conjugated secondary antibody. Shown in the top are representative fluorescence images of Akt immunostaining at the NMJ of wild type (WT) and $a k t^{4226}$. Under the color images are inverted images of the corresponding fluorescence images (see Materials and Methods). Comparison of staining intensity between wild type and $a k t^{4226}$ is shown in enlarged images of synaptic boutons and nerve branches (corresponding to the boxes in the fluorescence images and inverted images). Note that the difference in staining intensity between wild type and the mutant appears to be more apparent at the nerve branches. $n=4$ and 3 for WT and $a k t^{4226}$ respectively. Scale bars, $20 \mu \mathrm{m}$.

Ito M (2001) Cerebellar long-term depression: characterization, signal transduction, and functional roles. Physiol Rev 81:1143-1195.

Jan YN, Jan LY (1978) Genetic dissection of short-term and long-term facilitation at the Drosophila neuromuscular junction. Proc Natl Acad Sci USA 75:515-519.

Johansen J, Halpern ME, Johansen KM, Keshishian H (1989a) Stereotypic morphology of glutamatergic synapses on identified muscle cells of Drosophila larvae. J Neurosci 9:710-725.

Johansen J, Halpern ME, Keshishian H (1989b) Axonal guidance and the development of muscle fiber-specific innervation in Drosophila embryos. J Neurosci 9:4318-4332.

Keshishian H, Broadie K, Chiba A, Bate M (1996) The Drosophila neuromuscular junction: a model system for studying synaptic development and function. Annu Rev Neurosci 19:545-575.

Kidokoro Y, Kuromi H, Delgado R, Maureira C, Oliva C, Labarca P (2004) Synaptic vesicle pools and plasticity of synaptic transmission at the Drosophila synapse. Brain Res Brain Res Rev 47:18-32.

Koenig JH, Ikeda K (1999) Contribution of active zone subpopulation of vesicles to evoked and spontaneous release. J Neurophysiol 81:1495-1505.

Kurdyak P, Atwood HL, Stewart BA, Wu CF (1994) Differential physiology and morphology of motor axons to ventral longitudinal muscles in larval Drosophila. J Comp Neurol 350:463-472.

Kuromi H, Kidokoro Y (2000) Tetanic stimulation recruits vesicles from reserve pool via a cAMP-mediated process in Drosophila synapses. Neuron 27:133-143.

Levin LR, Han PL, Hwang PM, Feinstein PG, Davis RL, Reed RR (1992) The Drosophila learning and memory gene rutabaga encodes a $\mathrm{Ca}^{2+}$ / calmodulin-responsive adenylyl cyclase. Cell 68:479-489.

Lnenicka GA, Atwood HL (1985) Long-term facilitation and long-term adaptation at synapses of a crayfish phasic motoneuron. J Neurobiol 16:97-110.

Lnenicka GA, Keshishian H (2000) Identified motor terminals in Drosophila larvae show distinct differences in morphology and physiology. J Neurobiol 43:186-197.

Lo YJ, Lin YC, Sanes DH, Poo MM (1994) Depression of developing neuromuscular synapses induced by repetitive postsynaptic depolarizations. J Neurosci 14:4694-4704.

Malenka RC, Nicoll RA (1999) Long-term potentiation-a decade of progress? Science 285:1870-1874.

Packard M, Mathew D, Budnik V (2003) FAST remodeling of synapses in Drosophila. Curr Opin Neurobiol 13:527-534.

Presente A, Boyles RS, Serway CN, de Belle JS, Andres AJ (2004) Notch is required for long-term memory in Drosophila. Proc Natl Acad Sci USA 101:1764-1768.

Renger JJ, Ueda A, Atwood HL, Govind CK, Wu CF (2000) Role of cAMP cascade in synaptic stability and plasticity: ultrastructural and physiological analyses of individual synaptic boutons in Drosophila memory mutants. J Neurosci 20:3980-3992.

Rohrbough J, Pinto S, Mihalek RM, Tully T, Broadie K (1999) latheo, a Drosophila gene involved in learning, regulates functional synaptic plasticity. Neuron 23:55-70.

Rohrbough J, Grotewiel MS, Davis RL, Broadie K (2000) Integrin-mediated regulation of synaptic morphology, transmission, and plasticity. J Neurosci 20:6868-6878.

Sanyal S, Sandstrom DJ, Hoeffer CA, Ramaswami M (2002) AP-1 functions upstream of CREB to control synaptic plasticity in Drosophila. Nature 416:870-874

Scanga SSE, Ruel L, Binari RC, Snow B, Stambolic V, Bouchard D, Peters M, Calvieri B, Mak TW, Woodgett JR, Manoukian AS (2000) The conserved PI3'K/PTEN/Akt signaling pathway regulates both cell size and survival in Drosophila. Oncogene 19:3971-3977.

Schwarz TL (1994) Genetic analysis of neurotransmitter release at the synapse. Curr Opin Neurobiol 4:633-639.

Sigrist SJ, Thiel PR, Reiff DF, Lachance PE, Lasko P, Schuster CM (2000) Postsynaptic translation affects the efficacy and morphology of neuromuscular junctions. Nature 405:1062-1065.

Sigrist SJ, Thiel PR, Reiff DF, Schuster CM (2002) The postsynaptic glutamate receptor subunit DGluR-IIA mediates long-term plasticity in Drosophila. J Neurosci 22:7362-7372.

Sigrist SJ, Reiff DF, Thiel PR, Steinert JR, Schuster CM (2003) Experiencedependent strengthening of Drosophila neuromuscular junctions. J Neurosci 23:6546-6556.

Spradling AC, Stern D, Beaton A, Rhem EJ, Laverty T, Mozden N, Misra S, Rubin GM (1999) The Berkeley Drosophila genome project gene disruption project: single P-element insertions mutating $25 \%$ of vital Drosophila genes. Genetics 153:135-177.

Staveley BE, Ruel L, Jin J, Stambolic V, Mastronardi FG, Heitzler P, Woodgett JR, Manoukian AS (1998) Genetic analysis of protein kinase B (Akt) in Drosophila. Curr Biol 8:599-602.

Stevens CF, Sullivan JM (1998) Regulation of the readily releasable vesicle pool by protein kinase C. Neuron 21:885-893.

Stewart BA, Atwood HL, Renger JJ, Wang J, Wu CF (1994) Improved stability of Drosophila larval neuromuscular preparations in haemolymphlike physiological solutions. J Comp Physiol A Neuroethol Sens Neural Behav Physiol 175:179-191.

Stocker H, Andjelkovic M, Oldham S, Laffargue M, Wymann MP, Hemmings BA, Hafen E (2002) Living with lethal PIP3 levels: viability of flies lacking PTEN restored by a PH domain mutation in Akt/PKB. Science 295:2088-2091.

Thiels E, Kanterewicz BI, Norman ED, Trzaskos JM, Klann E (2002) Longterm depression in the adult hippocampus in vivo involves activation of extracellular signal-regulated kinase and phosphorylation of Elk-1. J Neurosci 22:2054-2062.

Tyler WJ, Pozzo-Miller LD (2001) BDNF enhances quantal neurotransmit- 
ter release and increases the number of docked vesicles at the active zones of hippocampal excitatory synapses. J Neurosci 21:4249-4258.

Vactor DV, Sink H, Fambrough D, Tsoo R, Goodman CS (1993) Genes that control neuromuscular specificity in Drosophila. Cell 73:1137-1153.

Wan J, Poo M (1999) Activity-induced potentiation of developing neuromuscular synapses. Science 285:1725-1728.

Wang Q, Liu L, Pei L, Ju W, Ahmadian G, Lu J, Wang Y, Liu F, Wang YT (2003) Control of synaptic strength, a novel function of Akt. Neuron 38:915-928.

Waters J, Smith SJ (2000) Phorbol esters potentiate evoked and spontaneous release by different presynaptic mechanisms. J Neurosci 20:7863-7870.
Wu MN, Bellen HJ (1997) Genetic dissection of synaptic transmission in Drosophila. Curr Opin Neurobiol 7:624-630.

Wu Y, Kawasaki F, Ordway RW (2005) Properties of short-term synaptic depression at larval neuromuscular synapses in wild-type and temperature-sensitive paralytic mutants of Drosophila. J Neurophysiol 93:2396-2405.

Zhong Y, Pena LA (1995) A novel synaptic transmission mediated by a PACAP-like neuropeptide in Drosophila. Neuron 14:527-536.

Zhong Y, Wu CF (1991) Alteration of four identified K+ currents in Drosophila muscle by mutations in eag. Science 252:1562-1564.

Zucker RS, Regehr WG (2002) Short-term synaptic plasticity. Annu Rev Physiol 64:355-405. 